УДК 316.473

DOI 10.18413/2712-746X-2020-44-2-237-246

\title{
Формирование позитивной этнической идентичности в моноэтничном регионе
}

\author{
Анциферова И.В., Анциферова Н.Г. \\ Курская академия государственной и муниципальной службы, \\ Россия, 308044, г. Курск, ул. Станционная, 9 \\ E-mail: nataly106@yandex.ru
}

\begin{abstract}
Аннотация. На основе данных социологического исследования проанализированы уровень этнической толерантности и тип этнической идентификации жителей моноэтничного региона. Раскрыта сущность понятий «этническая толерантность» и «этническая идентификация», показано влияние типа этнической идентичности на уровень этнической толерантности. Приведена классификация регионов по этническому составу. Проанализированы основные проблемы межэтнического взаимодействия в моноэтничном регионе. Опираясь на полученные выводы, авторы разработали меры по формированию позитивной этнической идентичности, которые описывают возможности широкого круга акторов межэтнического взаимодействия в указанном процессе. Особо подчеркивается роль национальных объединений в транслировании своей культуры в иноэтничной среде и важность этого процесса в формировании позитивной этнической идентичности принимающего сообщества.
\end{abstract}

Ключевые слова: этнос, национальная культура, этническая толерантность, этническая идентичность, моноэтничный регион, межэтническое взаимодействие, интолерантность, социальная идентификация, этнические процессы, миграция.

Для цитирования: Анциферова И.В., Анциферова Н.Г. 2020. Формирование позитивной этнической идентичности в моноэтничном регионе. NOMOTHETIKA: Философия. Социология. Право. 45 (2): 237-246. DOI 10.18413/2712-746X-2020-44-2-237-246

\section{The formation of a positive ethnic identity in a mono-ethnic region}

\author{
Irina V. Antsiferova, Natalya G. Antsiferova \\ Kursk Academy of State and Municipal Service, \\ 9 Stantsionnaya St, Kursk, 308044, Russia \\ E-mail: nataly106@yandex.ru
}

\begin{abstract}
On the basis of sociological research there was analyzed the level of ethnic tolerance and the type of ethnic identification in the mono-ethnic region. The authors revealed the essence of the concept «ethnic tolerance» and «ethnic identification». After analyzing the types of ethnic identification, the authors concluded that positive ethnic identification affects ethnic tolerance and negative identification provokes intolerance. Also there is given a classification of regions by their ethnicity. The authors convincingly prove that the mono-ethnic regions are experiencing problems in inter-ethnic interaction in modern conditions. Based on the findings, the authors developed measures for the formation of a positive ethnic identity. These measures describe the possibilities of a wide range of actors of inter-ethnic interaction in this process. The role of national associations in broadcasting their culture in a non-ethnic environment and the role of this process in the formation of a positive ethnic identity of the host community is emphasized.
\end{abstract}


Recommendations are also given for the authorities and civil society involved in this process. The article is of interest to a wide range of researchers.

Keywords: ethnos, national culture, ethnic tolerance, ethnic identity, mono-ethnic region, interethnic interaction, tolerance, social identification, ethnic processes, migration.

For citation: Antsiferova I.V., Antsiferova N.G. 2020. The formation of a positive ethnic identity in a mono-ethnic region. NOMOTHETIKA: Philosophy. Sociology. Law series. 45 (2): 237-246 (in Russian). DOI 10.18413/2712-746X-2020-44-2-237-246

\section{Введение}

В современном российском обществе вопросы межэтнического взаимодействия не теряют своей актуальности. Исследователи продолжают спорить о том, какой путь гармонизации межэтнических отношений наиболее перспективен. При этом большинство ученых сходятся во мнении о необходимости формирования позитивной идентичности. Особую актуальность эта задача приобретает в условиях поиска путей формирования и развития этнической толерантности в современном обществе.

Тема взаимного влияния этнической идентичности и этнической толерантности давно изучается российскими исследователями. Научно обосновано детерминирующее воздействие групповой этнической идентификации на толерантное (интолерантное) отношение к представителям иных этнических групп. Сформулирован социально-психологический закон, согласно которому позитивная этническая идентичность соответствует высокому уровню этнической толерантности, а негативные установки по отношению к собственной этнической группе значительно увеличивают интолерантные настроения, вплоть до отказа от межэтнического взаимодействия либо провоцирования конфликтных ситуаций. Более того, даже неопределенность этнической идентичности будет продуцировать негативные установки на межэтническое взаимодействие. Таким образом, гармоничное межкультурное взаимодействие в большой мере зависит от комплекса социально-психологических установок по отношению к своей этнической общности, которые реализуются в поведенческих стратегиях большинства членов этой группы [Скоробогатая, 2008].

\section{Обзор научных источников}

Для понимания механизма взаимодействия этнической идентичности и толерантности целесообразно подробно рассмотреть процесс формирования этнической толерантности. Существует несколько точек зрения на определение данного явления.

В широком смысле под толерантностью понимают принятие иного, восприятие иноэтничной культуры и отсутствие негативных установок по отношению к ним. Ядром данной социально-психологической установки является отсутствие противопоставления «мы - они» и равноценное отношение к иной и собственной этничности [Татарко, Лебедева, 2010]. Другое направление определяет толерантность как некое множество социальнопсихологических установок, дифференцированных по возрастанию негативного восприятия иной этничности от толерантности к интолерантности. Н.М. Лебедева определяет этническую толерантность как наличие позитивного образа представителей иной культуры при наличии позитивного образа собственной культуры [Лебедева, 2016]. При этом толерантная этническая установка не предполагает растворения в иной культуре, ее полное принятие, а является проявлением ассертивного группового поведения, осознания равенства культур и восприятия их различий как положительного фактора, не несущего негативных последствий.

В.А. Тишков рассматривает этническую толерантность с других позиций. Он понимает ее как постоянное и направленное усилие на конструирование и осуществление опре- 
деленных личностных и общественных ценностей и норм поведения [Тишков, 1997]. В данном подходе толерантность рассматривается как личная установка, приобретаемая в ходе получения жизненного опыта, социализации индивида и как действие, предполагающее самоограничение и намеренное невмешательство. В рамках такого подхода толерантность присуща только зрелой личности и является условием существования сложных обществ. Толерантность не является врожденным свойством человека, она также не может быть перманентной характеристикой общества и существует только в условиях постоянного намеренного культивирования. Данное определение описывает толерантность не с позиций отношения к иному, а с позиций поиска способа выхода из ситуации противопоставления культур.

Вопрос о выделении уровней этнической толерантности также является дискуссионным. Большинство исследователей сходятся во мнении, что уровни этнической толерантности целесообразно ранжировать по шкале «толерантность - интолерантность». Выделяются протекционистская толерантность, включающая не только полное принятие иного, но и желание предотвратить его дискриминацию, проявления интолерантности; ценностная толерантность, имеющая в основе систему ценностей, опирающуюся на признание равноправия всех культур и жесткое подчинение этому принципу; скрытая интолерантность, основанная на боязни общественного осуждения интолерантного поведения либо высказываний, но не исключающая наличие внутренней предвзятой установки по отношению к иному; вербальная интолерантность, предполагающая возможным публичные высказывания интолерантного характера, но не допускающая публичные действия; агрессивная поведенческая интолерантность - совершение действий дискриминационного характера либо отказ от межэтнического взаимодействия [Попов, 2008].

Факторы формирования этнической толерантности зависят от структуры толерантности. Так, когнитивный элемент структуры толерантности формируется под влиянием «пересекающегося» членства в социальной группе, принадлежности к группе меньшинства, принятия гражданской идентичности, неопределенности этнической идентичности. Эмоциональная составляющая структуры толерантности зависит от ценности социальной интеграции, выраженности этнической идентичности. На деятельностный элемент структуры толерантности влияют желание единства и принятие культурного разнообразия, установка на кооперацию, позитивную этническую идентичность или негативные чувства, связанные с этничностью [Коряпина, 2011]. Таким образом, этническая идентичность является фактором формирования каждого элемента структуры толерантности.

Для того чтобы проследить социально-психологический механизм взаимодействия этнической идентичности и толерантности, необходимо определить понятие «этническая идентичность». Этническая идентичность является компонентом социальной идентичности личности. В процессе социализации личность относит все социальные объекты к отдельным классам. Социальная категоризация позволяет личности устанавливать границы между собой и окружающими. В результате этого самоопределения у личности формируется социальная идентичность. В процессе межкультурных контактов у индивида вырабатывается система представлений о сходстве и различиях этнических групп. На основе этой этнической категоризации и формируется этническая идентичность [Стефаненко, 2006].

Таким образом, этническая идентичность - это результат отнесения себя к определенной этнической группе на основе соотнесения себя с иными группами. В отечественных исследованиях также существует точка зрения, что этническая идентичность - это зрелый уровень этнического самосознания [Хотинец, 2000]. Еще одна позиция определяет этническую идентичность как врожденное свойство соотносить себя с этнической группой [Семина, 2018].

В структуре этнической идентичности принято выделять аффективный, когнитивный и поведенческий компоненты, а также бессознательную составляющую. В когнитивном компоненте заложены знания о своей этнической группе, этнодифференцирующие 
признаки и осознание себя членом этой группы. Аффективный компонент содержит чувство принадлежности, оценку группы и отношение к нахождению в ней. Поведенческий компонент заключается в проявлении себя как члена группы в ситуации межкультурного взаимодействия. Так как аффективный компонент предполагает оценочное отношение к этничности, то этническая идентичность может быть позитивной либо негативной. Когнитивный компонент позволяет говорить о степени ясности, с которой личность осознает себя членом этнической группы [Ершова, Мурсатова, 2018]. В научных исследованиях эти параметры этнической идентичности получили названия валентность и определенность [Татарко, Лебедева, 2010].

Проводя анализ этнической идентичности по параметрам валентности и определенности, можно выделить ее типы: нормальная (позитивная) идентичность, этноцентрическая идентичность, этнодоминирующая идентичность, этнический фанатизм, этническая индифферентность, этнонигилизм, амбивалентная идентичность [Карпенко, 2018, c. 78]. В данной классификации отсутствует выделение негативной идентичности, связанной с чувствами стыда, неполноценности, появляющимися при осознании себя членом этнической группы. Между тем именно понимание феномена негативной этнической идентичности дает представление о ее взаимосвязи с этнической толерантностью или интолерантностью [Солдатова, Чигарькова, 2016].

Рассмотрим механизм взаимосвязи этнической идентичности и толерантности. Исследователи полагают, что негативная этническая идентичность возникает в ситуации утраты этнической группой позитивной оценки себя, ощущения себя как целостного этнического образования, размывания этнической определенности. Одновременно с этим возникает чувство потери себя, неполноценности и неспособности конфигурации окружающего социального пространства. Стремясь к выходу из этой ситуации, этническая группа ищет пути конструирования нового самосознания, самый простой из которых размежевание с иными культурами, повышение уровня своей этнической идентификации за счет отрицания иных культур. Именно поэтому негативная этническая идентичность ведет к появлению интолерантных установок в ситуации межэтнического взаимодействия. Немалую роль играет здесь и процесс дифференциации по типу «мы - они». В такой ситуации сравнение себя с иной группой происходит по принципу поиска исключительно негативных характеристик, а возврат к негативной исторической памяти и обвинение иной группы во всех своих неудачах приводят к формированию синдрома ущербной агрессивности и постоянному поиску врага [Goncharov, 2017]. В этом случае необходимо помочь группе восстановить позитивную идентичность, что снизит уровень интолерантности. Позитивная этническая идентичность позволяет группе избежать этнической категоризации по негативному сценарию. Группа с позитивной идентичностью не испытывает необходимости в поиске врага для оправдания своей ущербности и дифференцирует социальное пространство с позиций поиска различий между группами при четком осознании того, что этнические различия не несут угроз, а являются естественным явлением [Зуйкова, 2019].

Таким образом, этническая идентичность является ядром этнической толерантности. Зная особенность этого социально-психологического феномена, можно разработать стратегии поддержания позитивного уровня этнической идентификации и возврата группе позитивной идентификации в случае ее утраты.

Необходимо отметить, что, несмотря на большое количество междисциплинарных исследований, посвященных влиянию этнической идентичности на характер межэтнического взаимодействия, большинство из них проводятся в полиэтничных российских регионах. В то же время в России имеется достаточное количество моноэтничных регионов с однородным национальным составом [Буфетова, Коломак, 2017]. В таких условиях очевидна невозможность применения единого подхода к механизмам гармонизации межна- 
циональных отношений на уровне российских регионов, необходимость разработки региональных стратегий с учетом уровня этнической однородности.

Для более глубокого понимания особенностей развития этнонациональных процессов в моноэтничных регионах обратимся к характеристике этнического пространства России. Выделяют три вида российских регионов по их этническому составу: «русское мегаядро» - территории с преобладающей долей русского населения (более 80 \%); национальные регионы - регионы с сильной этнической неоднородностью; переходные этноконтактные зоны - регионы «русского мегаядра» с изменчивой, усложняющейся этнической структурой. Находясь на периферии «ядра», эти регионы испытывают в последнее время миграционный прирост, связанный с событиями в зарубежных странах и с экономической привлекательностью этих регионов для мигрантов. К этноконтактным зонам относятся и крупные города с неоднородным этническим составом [Сафонов, 2015]. Очевидно, что усложнение этнической структуры, миграционный прирост, увеличение частоты межэтнических контактов, активность приезжих на рынке труда и появление компактно проживающих иноэтничных групп являются для данных регионов новыми явлениями. Этническая мозаичность становится для коренного населения этих регионов фактором стресса, неопределенности и чревата появлением конфликтов.

Для выработки механизмов формирования позитивной этнической идентичности в моноэтничном регионе нам необходимо опереться на исследования состояния межнациональных отношений в этноконтактоной зоне.

\section{Объекты и методы исследования}

Исследование проблемы формирования позитивной этнической идентичности в моноэтничном регионе «Межнациональные и межконфессиональные отношения населения Курской области в период 2017-2019 годов» было проведено в Курской области Центром регионального развития ГОАУ ВО Курской области «Курская академия государственной и муниципальной службы». В качестве генеральной совокупности выступило население Курской области в возрасте от 18 лет и старше, составляющее 937389 человек в 2017 году 928283 - в 2018 году и 922222 человек в 2019 году. Выборочная совокупность респондентов в 2017 году составила 380 человек при доверительной вероятности $95 \%$ и доверительном интервале $5 \%$. В исследовании 2018 года при репрезентативности выборки в 1820 человек доверительная вероятность установилась на уровне 99 \%, а доверительный интервал - 3 \%. Выборочная совокупность респондентов в 2019 году составила 630 человек при доверительной вероятности $99 \%$ и доверительном интервале $5 \%$.

Исследование проводилось методом интервьюирования населения и методом анкетирования по месту работы и месту жительства респондентов. Контроль качества осуществлялся посредством постоянного анализа качества результатов анкет, проверялись полнота и правильность заполнения.

\section{Результаты и их обсуждение}

Определенный интерес представляет подтверждение существующей взаимосвязи и взаимозависимости между этнической идентификацией и толерантностью на основе эмпирических данных. При анализе этого явления необходимо учитывать национальную структуру страны или региона, степень принятия коренными жителями в своей среде людей другой национальности, восприятия иных культур и вероисповеданий.

В Курской области проживают представители 140 национальностей, при этом доля титульной нации составляет 91,97 \%. Свою деятельность осуществляют 10 национальнокультурных организаций и 350 религиозных организаций и конфессий. Трудовая миграция невелика в количественных показателях и носит преимущественно транзитный характер. Регион имеет границу с Украиной. Приведенные характеристики позволяют отнести 
его к числу моноэтничных приграничных регионов, что определят некую специфику как этнической толерантности, так и идентификации граждан.

Данные мониторинга показывают, что у населения региона превалируют доброжелательные чувства к людям другой национальности. В 2017 году на это указало 47,9 \% респондентов, в 2018 и 2019 годах - соответственно 47,7 и 35,6 \%. Чувство безразличия выразили соответственно $33,6,32,9,46,5 \%$ респондентов, чувство неприязни соответственно - 6,3, 3,8, $12 \%$. Обращает на себя внимание существенное снижение позитивных оценок в восприятии людей другой национальности в 2019 году при увеличении уровня неприязни и безразличия в среднем на десять пунктов. Это явление прежде всего фиксируется в приграничных районах области и связано с имеющимися напряженными отношениями с соседним государством. Жители муниципальных образований региона, не относящихся к приграничной территории, более дружественно воспринимают людей другой национальности. Доброжелательное отношение в 2019 году выразили 45,7 \% респондентов, проживающих в приграничных муниципальных образованиях Курской области и 49,7 \% проживающих в иных муниципальных образованиях. Соответственно неприязненные чувства к людям другой национальности испытывают 2,7 и 4,8 \% респондентов.

Анализ состояния этнической толерантности будет неполным без учета мнений респондентов по поводу их отношения к трудовым мигрантам, прибывшим из стран ближнего зарубежья. За последние три года среднегодовая численность трудовых мигрантов, прибывших в регион, составляет около 10000 человек. Основными местами их размещения являются областной и районные центры, поселки городского типа. На протяжении исследуемого периода результаты опроса фиксируют наиболее доброжелательные чувства к мигрантам из Белоруссии и Украины. Доброжелательно к трудовым мигрантам из Белоруссии относились в 2017 году 57,2 \%, в 2018 году - 46,2 \%, в 2019 году - 60,3 \%; к мигрантам, прибывшим из Украины, соответственно - 46,6, 33,4, 36,2\%. Чувства неприязни отмечены к представителям Туркменистана, соответственно - 8,3, 14,1, 24,8 \%, и Таджикистана - 11,5, 13,5, 24,3 \%.

Стоит отметить, что показатели уровня доброжелательности и неприязни в исследованиях 2019 года существенно выросли. Жители региона с большей доброжелательностью стали относиться к мигрантам из Белоруссии и Украины и большую неприязнь испытывать к представителям азиатских стран. Увеличение разрыва между показателями уровня доброжелательности и неприязни к людям другой национальности в лице трудовых мигрантов говорит о том, что наряду с другими факторами, в том числе экономическими, трудовой занятости, демографическими, не последнюю роль играет этническая идентификация жителей региона. Они в большей степени отождествляют себя с людьми другой национальности, более близкой по культуре, языку, вероисповеданию. То есть при достаточно высоком показателе уровня этнической толерантности вообще к представителям неблизкой этнокультурной группы уровень терпимости респондентов резко падает.

Подтверждением тому служат ответы респондентов на вопрос «Почему вам некомфортно жить по соседству с людьми другой национальности?». На протяжении трех лет наиболее часто встречающимися ответами по мере убывания их значимости были следующие: «Они не уважают наши обычаи и традиции», «Они ведут себя оскорбительно по отношению к людям нашей национальности», «Они живут по иному укладу жизни, говорят на непонятном языке».

Интерес к культуре других народов, знание их обычаев жизненного уклада раскрывает содержательную составляющую толерантности, степень осознанности данного чувства. Данные мониторинга показывают высокий уровень информированности респондентов об обычаях и традициях других народов, на что указали 52,3 \% опрошенных в 2017 г., 55,5 \% в 2018 г., 50,4 \% в 2019 г. На отсутствие интереса к культуре других народов соответственно указали 4,6, 7,9, 9,0 \% респондентов. 
Выявлено наличие высокой степени уважения к культуре других народов, на которое указывают более 50 \% респондентов на протяжении трех лет [Официальный социологический портал Курской области]. Данный факт говорит о наличии сформированной основы толерантного отношения жителей Курской области к людям другой национальности. Учитывая, что этническая толерантность и идентификация находятся в прямой зависимости, с большой долей вероятности можно говорить о том, что на процесс идентификации жителей региона позитивное влияние оказывает межкультурный обмен.

Процесс поддержания указанного уровня этнической идентичности и соответствующего ей типа толерантности возможен на основе разработки региональной стратегии, включающей в себя комплекс мер, затрагивающих различные сферы жизнедеятельности общества. Прежде всего, целесообразно использовать возможности образовательных учреждений. Изучение обязательных предметов (история, литература, краеведение) и внеурочная работа (традиционные праздники, приобщение к традициям) непосредственно формируют знания о своем этносе. Более широкие мероприятия, направленные на поддержание позитивной этнической идентичности, включают научные конференции и дискуссии о национальной культуре, проведение городских и сельских мероприятий, связанных с национальной культурой (Масленичные гулянья, рождественский фестиваль) [Skvortsov, 2017].

Немалую роль играют средства массовой информации, интернет-ресурсы, национальные объединения. Так, региональные телеканалы могут разработать ряд передач об истории формирования и развития России как многонационального государства, информировать о культуре, обычаях и языках народов России, приглашать представителей национальных объединений, делать сюжеты о жизни представителей национальных диаспор региона, при этом проводя параллели с русским этносом, расставляя акценты на сходствах культур, подчеркивая взаимовлияние [Шатаева и др., 2015]. Так как представители молодежи не являются основной аудиторией телевизионных каналов, целесообразно работать с этой группой, привлекая интернет-ресурсы, популярные в молодежной среде. Они могут размещать информацию об этнических особенностях в привлекательной для молодежной аудитории форме видеороликов, подкастов, привлекать аудиторию социальных сетей к диалогу.

Большую роль в распространении информации об этнических особенностях и различиях этносов играют национальные объединения регионов. С одной стороны, они способны создавать ситуации межэтнического общения, налаживать конструктивное взаимодействие коренных жителей с обособленными этническими группами. Необходимо проводить мероприятия, направленные на диалог, реальное общение, обсуждение ключевых моментов взаимодействия. На площадках для диалога должны обсуждаться вопросы исторической памяти, современные межнациональные отношения этносов, проблемы совместного существования двух этносов на одной территории и иные. С другой стороны, национальные объединения участвуют в процессе адаптации новых членов. Содержание программ адаптации должно основываться на близости базовых ценностей этносов, освещать положительную роль принимающего этноса в истории страны исхода [Frants, 2016].

Необходимо акцентировать внимание на том, что возвышение роли своего этноса, преподнесение своей национальной культуры как превалирующей над другими оказывают негативное влияние на этническую идентичность. Главная возможность поддерживать позитивный уровень этнической идентичности состоит в формировании интегрирующих ценностей. Они могут быть связаны с общей исторической судьбой народов, населяющих нашу страну, наполнением общенациональных праздников новым содержанием, раскрывающим роль народов России в судьбе страны, акцентированием позитивных моментов в многонациональном составе, декларированием гармонии в единстве и многообразии [Goncharov, 2016]. 


\section{Выводы}

Данные исследования позволяют сделать вывод о том, что между уровнем этнической толерантности и типом этнической идентификации существует определенная взаимосвязь. Позитивная этническая идентичность, которая характеризуется отсутствием потребности в поиске «врага» и дифференциации социального пространства с позиции поиска различий между группами, детерминирует ценностную толерантность, которая отличается наличием системы ценностей, основанной на признании равноправия всех культур.

Проведенный анализ результатов социологического исследования выявил, что у населения региона превалируют доброжелательные чувства к людям другой национальности, граждане способны отождествлять себя с иными. Уровень интереса и уважения к культуре других народов, их обычаям, жизненным укладам достаточно высок. В целом можно говорить о наличии сформированной у жителей Курской области этнической толерантности ценностного уровня, в основе которой находится позитивная этническая идентичность.

Основываясь на взаимозависимости типов этнической идентификации и уровней этнической толерантности можно разрабатывать региональные стратегии поддержания толерантности определенного уровня, учитывая при этом степень этнической однородности региона. Таким образом, общественная практика межэтнического взаимодействия обогатится новыми тенденциями в сферах коммуникации, культуры, образования.

\section{Список источников}

1. Официальный социологический портал Курской области. [Электронный ресурc]. URL: http://xn--46-6kc8bnagjfo4b.xn--p1ai/report/ (дата обращения: 18 февраля 2020).

2. Стефаненко Т.Г. 2006. Этнопсихология: практикум: учебное пособие для студентов вузов. М., Аспект Пресс: 208

3. Лебедева Н.М. 2016. Этнопсихология: учебник и практикум для академического бакалавриата. М., Издательство Юрайт: 491 с.

\section{Список литературы}

1. Буфетова А.Н., Коломак Е.А. 2017. Национальная неоднородность в регионах России. ЭКО, 47(4): 110-123.

2. Ершова Н.Н., Мурсатова Н.Ю. 2018. Структура социальной идентичности у студентов. В кн.: Инновационные технологии в науке и образовании. Сборник статей VI Международной научно-практической конференции (Пенза, 5 ноября 2017 г.). Пенза, Наука и Просвещение: 198-200.

3. Зуйкова А.А. 2019. Особенности этнической идентичности, связь с самооценкой личности. Человек. Социум. Общество, 3: 57-60.

4. Карпенко 3.Р. 2018. Типы формирования этнической идентичности. В кн.: Реализация компетентностного подхода в системе профессионального образования педагога. Материалы V Всероссийской научно-практической конференции (Евпатория, 12-13 апреля 2018 г.). Симферополь, Общество с ограниченной ответственностью «Издательство Типография «Ариал»: 78-80.

5. Коряпина Ю.В.2011. К вопросу о когнитивном компоненте коммуникативной толерантности. Знание. Понимание. Умение, 2: 270-273.

6. Попов В.В. 2008. Этническая толерантность и методы определения границ толерантного отношения. В сб.: Материалы III Всероссийского социологического конгресса (Москва 21-24 октября 2008 г.). М., Институт социологии РАН, Российское общество социологов: 215-219.

7. Сафонов С.Г. 2015. Современные тенденции трансформации этнического состава населения России. Балтийский регион, 3(25): 138-153.

8. Семина Г.В. 2018. Этносы и нации: к вопросу об этничности (идентичности) в научных традициях отечественных и западных исследователей. Вопросы культурологи, 6: 10-19.

9. Скоробогатая А.А. 2008. Этническая идентичность и межкультурное взаимодействие в Северной Башкирии. М., ТЕИС: 190. 
10. Солдатова Г.У., Чигарькова С.В. 2016. Позитивная этническая идентичность как фактор успешного межкультурного взаимодействия. В кн.: Россия в мировом сообществе: смысловое пространство диалога культур. Материалы международного форума «Восточный вектор миграционных процессов: диалог с русской культурой» (Хабаровск, 16-17 ноября 2017 г.). Хабаровск, Тихоокеанский государственный университет: 487-490.

11. Татарко А.Н., Лебедева Н.М. 2010. Психология межэтнических отношений: этническая идентичность и стратегии межкультурного взаимодействия. Saarbrucken, LAPLAMBERT Academic Publishing GmbH \& Co: 177 c.

12. Тишков В.А. 1997. Толерантность и согласие в трансформирующихся обществах. М., Русский мир: $532 \mathrm{c.}$

13. Хотинец В.Ю. 2000. Этническое самосознание. СПб., Алетейя: 240 с.

14. Шатаева О.В., Коршунова Н.Е., Никитюк В.А. 2015. Этническая толерантность сотрудников организации г. Москвы. М, Прометей: 140 с.

15. Frants V. 2016. Ethnic identity as the migrants political identity element. In: AEON International Multidisciplinary Conference on Social Sciences and Arts (Venice, 30 September 03 October, 2016). Venice, Aeon Eood: 10-17.

16. Goncharov V.N. 2016. Ethnic identity in the context of development of society and state. In: Ethnocultural identity as a strategic resource of consciousness of society in the conditions of globalization. Materials of the IV international scientific conference (Prague, September 28-29, 2016). Prague, Vedecko vydavatelske centrum Sociosfera-CZ s.r.o.: 28-30.

17. Goncharov V.N. 2017. Ethnic russian identity in the context of interethnic tolerance. In: Ethnocultural identity as a strategic resource of consciousness of society in the conditions of globalization. Materials of the V international scientific conference (Prague, 28-29 September, 2017). Prague, Vedecko vydavatelske centrum Sociosfera-CZ s.r.o.: 10-13.

18. Skvortsov N. 2017. The Formation of National Identity in Contemporary Russia. Changing Societies \& Personalities. Special issue «Values: Continuities and Alterations», 1(1): 74-83.

\section{References}

1. Bufetova A. N., Kolomak E. A. 2017. Nacional'naja neodnorodnost' v regionah Rossii (National heterogeneity in the regions of Russia). JeKO, 47(4):110-123. (in Russian)

2. Ershova N.N., Mursatova N.Ju. 2018. Struktura social'noj identichnosti u studentov [Structure of social identity in students]. In: Innovacionnye tehnologii v nauke i obrazovanii. Sbornik statej VI Mezhdunarodnoj nauchno-prakticheskoj konferencii (Penza, 5 November, 2017). Penza, Nauka i Prosveshhenie: $198-200$.

3. Zujkova A.A. 2019. Osobennosti jetnicheskoj identichnosti, svjaz' s samoocenkoj lichnosti [Features of ethnic identity, connection with self-esteem of the individual]. Chelovek. Socium. Obshhestvo, 3: 57-60.

4. Karpenko Z.R. 2018. Tipy formirovanija jetnicheskoj identichnosti [Types of ethnic identity formation]. In: Realizacija kompetentnostnogo podhoda $\mathrm{v}$ sisteme professional'nogo obrazovanija pedagoga. Materialy V Vserossijskoj nauchno-prakticheskoj konferencii (Evpatorija, 12-13 April, 2018). Simferopol', Obshhestvo s ogranichennoj otvetstvennost'ju «Izdatel'stvo Tipografija «Arial»: 78-80.

5. Korjapina Ju.V.2011. K voprosu o kognitivnom komponente kommunikativnoj tolerantnosti [On the question of the cognitive component of communicative tolerance]. Znanie. Ponimanie. Umenie, 2: $270-273$.

6. Popov V.V. 2008. Jetnicheskaja tolerantnost' i metody opredelenija granic tolerantnogo otnoshenija [Ethnic tolerance and methods for determining the boundaries of tolerance]. In: Materialy III Vserossijskogo sociologicheskogo kongressa (Moskow 21-24 October, 2008). M., Institut sociologii RAN, Rossijskoe obshhestvo sociologov: 2015-2019.

7. Safonov S.G. 2015. Sovremennye tendencii transoformacii jetnicheskogo sostava naselenija Rossii [Current trends in the transformation of the ethnic composition of the Russian population]. Baltijskij region, 3(25): 138-153.

8. Semina G.V. 2018. Jetnosy i nacii: k voprosu ob jetnichnosti (identichnosti) v nauchnyh tradicijah otechestvennyh i zapadnyh issledovatelej [Ethnoses and Nations: on the question of ethnicity (identity) in the scientific traditions of Russian and Western researchers]. Voprosy kul'turologi, 6: 10-19.

9. Skorobogataja A.A. 2008. Jetnicheskaja identichnost' i mezhkul'turnoe vzaimodejstvie v Severnoj Bashkirii [Ethnic identity and intercultural interaction in Northern Bashkiria]. M., TEIS: 190. 
10. Soldatova G.U., Chigar'kova S.V. 2016. Pozitivna jetnicheskaja identichnost' kak faktor uspeshnogo mezhkul'turnogo vzaimodejstvija [Positive ethnic identity as a factor of successful intercultural interaction]. In: Rossija v mirovom soobshhestve: smyslovoe prostranstvo dialoga kul'tur. Materialy mezhdunarodnogo foruma «Vostochnyj vektor migracionnyh processov: dialog s russkoj kul'turoj» (Habarovsk, 16-17 November, 2017). Habarovsk, Tihookeanskij gosudarstvennyj universitet: 487-490.

11. Tatarko A.N., Lebedeva N.M. 2010. Psihologija mezhjetnicheskih otnoshenij: jetnicheskaja identichnost' i strategii mezhkul'turnogo vzaimodejstvija [Psychology of interethnic relations: ethnic identity and strategies for intercultural interaction]. Saarbrucken, LAPLAMBERT Academic Publishing GmbH \& Co: 177 p.

12. Tishkov V.A. 1997. Tolerantnost' i soglasie v transformirujushhihsja obshhestvah [Tolerance and consent in transforming societies]. M., Russkij mir: $532 \mathrm{p}$.

13. Hotinec V. Ju. 2000. Jetnicheskoe samosoznanie [Ethnic identity]. SPb., Aletejja: 240.

14. Shataeva O.V., Korshunova N.E., Nikityuk V.A. 2015. Etnicheskaya tolerantnost' sotrudnikov organizatsii g. Moskvy [Ythnic tolerance of employees of organizations in Moscow]. M, Prometey: 140.

15. Frants V. 2016. Ethnic identity as the migrants political identity element. In: AEON International Multidisciplinary Conference on Social Sciences and Arts (Venice, 30 September - 03 October, 2016). Venice, Aeon Eood: 10-17.

16. Goncharov V.N. 2016. Ethnic identity in the context of development of society and state. In: Ethnocultural identity as a strategic resource of consciousness of society in the conditions of globalization. Materials of the IV international scientific conference (Prague, September 28-29, 2016). Prague, Vedecko vydavatelske centrum Sociosfera-CZ s.r.o.: 28-30.

17. Goncharov V.N. 2017. Ethnic russian identity in the context of interethnic tolerance. In: Ethnocultural identity as a strategic resource of consciousness of society in the conditions of globalization. Materials of the V international scientific conference (Prague, 28-29 September, 2017). Prague, Vedecko vydavatelske centrum Sociosfera-CZ s.r.o.: 10-13.

18. Skvortsov N. 2017. The Formation of National Identity in Contemporary Russia. Changing Societies \& Personalities. Special issue «Values: Continuities and Alterations», 1(1): 74-83.

\section{ИНФОРМАЦИЯ ОБ АВТОРАХ}

Анциферова Ирина Владимировна, профессор кафедры государственного, муниципального управления и права Курской академии государственной и муниципальной службы, г. Курск, Россия

Анциферова Наталья Геннадьевна, доцент кафедры государственного, муниципального управления и права Курской академии государственной и муниципальной службы, г. Курск, Россия

\section{INFORMATION ABOUT THE AUTHORS}

Irina V. Antsiferova, professor of the Department of state, municipal administration and law, Kursk Academy of state and municipal service, Kursk, Russia

Natalya G. Antsiferova, docent of the Department of state, municipal administration and law, Kursk Academy of state and municipal service, Kursk, Russia 